\title{
How to Evolve a Perianth: A Review of Cadastral Mechanisms for Perianth Identity
}

\author{
Marie Monniaux* and Michiel Vandenbussche \\ Laboratoire Reproduction et Développement des Plantes, Université de Lyon, ENS de Lyon, UCB Lyon 1, CNRS, INRA, \\ Lyon, France
}

The flower of angiosperms is considered to be a major evolutionary innovation that impacted the whole biome. In particular, two properties of the flower are classically linked to its ecological success: bisexuality and a differentiated perianth with sepals and petals. Although the molecular basis for floral organ identity is well understood in extant species and summarized in the famous ABC model, how perianth identity appeared during evolution is still unknown. Here we propose that cadastral mechanisms that maintain reproductive organ identities to the center of the flower could have supported perianth evolution. In particular, repressing B- and C-class genes expression toward

OPEN ACCESS

Edited by: Annette Becker, Justus-Liebig-Universität Gießen,

Germany

Reviewed by:

Elena M. Kramer,

Harvard University, United States

Rainer Melzer,

University College Dublin, Ireland

*Correspondence:

Marie Monniaux

marie.monniaux@ens-lyon.fr

Specialty section:

This article was submitted to Plant Evolution and Development,

a section of the journal

Frontiers in Plant Science

Received: 18 June 2018 Accepted: 09 October 2018 Published: 29 October 2018

Citation:

Monniaux $M$ and Vandenbussche $M$ (2018) How to Evolve a Perianth: A Review of Cadastral Mechanisms for Perianth Identity. Front. Plant Sci. 9:1573. doi: $10.3389 /$ fpls.2018.01573 the inner whorls of the flower, is a key process to isolate domains with sepal and petal identity in the outer whorls. We review from the literature in model species the diverse regulators that repress $\mathrm{B}$ - and C-class genes expression to the center of the flower. This review highlights the existence of both unique and conserved repressors between species, and possible candidates to investigate further in order to shed light on perianth evolution.

Keywords: perianth, flower, evolution, petal, sepal, ABC model

\section{INTRODUCTION}

Flowering plants (angiosperms) gather more than 350,000 species, a stunning number in regard to all other land plants that count no more than 35,000 species (The Plant List, 2013). This dominance of angiosperms might be partly due to the flower, a highly efficient structure for reproduction (Regal, 1977). The flower has some key features such as bisexuality, a closed carpel, and a perianth (i.e., the structure that surrounds the reproductive organs, typically organized in sepals, and petals) that can attract pollinators and therefore participate in the speciation process (Fenster et al., 2004). This is mainly supported by the petals, that display a complex set of traits such as color, fragrance, shape, or epidermal cell patterns (Glover, 2014). Petals can also assist in flower opening (van Doorn and Van Meeteren, 2003), while sepals mainly protect the other floral organs. In this review we will use the term petal and sepal as a functional definition for all petaloid (showy and playing an attractive role) and sepaloid (greenish and playing a protective role) organs, respectively, irrespective of their position in the flower. With this definition, all petals (and all sepals) are therefore not necessarily homologous organs (Ronse De Craene and Brockington, 2013).

Although recent research has led to considerable progress on the question of the origin of the flower (Moyroud et al., 2017; Sauquet et al., 2017), large questions are still open. 
In particular, the timing and order of events leading from the reproductive structure of the most recent common ancestor of seed plants - likely a unisexual structure without perianth to the ancestral flower - likely a bisexual flower with an undifferentiated perianth of petals - is still unknown (Sauquet and Magallón, 2018). These events include transition from unisexuality to bisexuality, compression of the reproductive axis, evolution of a perianth and evolution of a closed carpel (Specht and Bartlett, 2009; Sauquet and Magallón, 2018; Scutt, 2018). Despite this uncertainty it seems reasonable to assume that the perianth evolved last, after bisexuality, axis compression and carpel evolution (Baum and Hileman, 2007). Later, the perianth often differentiated into an outer whorl of sepals and an inner whorl of petals (resulting in a so-called differentiated or bipartite perianth), which is particularly representative of core eudicots (Specht and Bartlett, 2009).

The origin of the perianth is still unresolved, but anatomical and developmental observations can shed some light on it. Sepals from most angiosperms have a leaf-like appearance suggesting they have a direct bract or leaf origin. Petals likely arose multiple times during evolution (Kramer and Irish, 2000) with two possible origins: bracteopetals that evolved from bracts and andropetals that evolved from stamens. Bracteopetals are typically observed in basal angiosperms that show a continuous differentiation between bracts and petaloid organs (Ronse De Craene, 2007). In contrast andropetals appear restricted to a few clades (Ranunculales and Caryophyllales for instance) where petals have probably been lost and reinvented (Ronse De Craene, 2007; Brockington et al., 2012; Ronse De Craene and Brockington, 2013). However, for most angiosperm species, the origin of petals remains unclear and a combination of anatomical and genetic work are needed to discriminate between the two possibilities.

Genetic work on model species have provided molecular support for the key events accompanying flowering: formation of the flower meristem, specification of floral organ identities (the famous $\mathrm{ABC}$ model), floral organ outgrowth and maturation, and fertilization (Glover, 2014). Based on this data, molecular models for the evolution of floral structures such as the bisexual axis have been proposed (Baum and Hileman, 2007; Frohlich and Chase, 2007; Specht and Bartlett, 2009). A similar approach can be followed to generate molecular hypotheses for the origin of the perianth; more specifically to speculate how an identity domain for the perianth could have emerged from an ancestral flower containing only reproductive organs. Here we propose that cadastral mechanisms maintaining reproductive identity to the center of the flower could have supported perianth appearance during evolution. Based on genetic work in model species, we review some of the molecular players underlying these cadastral mechanisms.

\section{CREATING A DOMAIN FOR PERIANTH IDENTITY}

Assuming that the perianth was the last angiosperm synapomorphy to appear, we have asked the following question
(Figure 1): how could a typical flower with 4 organ identities have been generated from a bisexual perianth-less flower with 2 organ identities?

In Figure 1, we use a genetic framework based on the (A)BC or FBC models proposed by Causier et al. or Baum and Hileman, respectively, where $(\mathrm{A})$ or $\mathrm{F}$ is a floral identity function acquired at early stages of floral meristem development and necessary for all floral organ identities (Baum and Hileman, 2007; Causier et al., 2010). We chose not to use the classical ABC model because the existence of the A function is much debated (Schwarz-Sommer et al., 1990; Litt, 2007; Causier et al., 2010; Heijmans et al., 2012; Morel et al., 2017). With the (A)BC framework, floral organ identities from a typical angiosperm flower are specified by a combination of (A) expression for sepals, (A) + B for petals, (A) $+\mathrm{B}+\mathrm{C}$ for stamens and $(\mathrm{A})+\mathrm{C}$ for carpels. Similarly, we can assume that the perianth-less ancestral flower had floral organ identities specified by $(\mathrm{A})+\mathrm{B}+\mathrm{C}$ for stamens and (A) + C for carpels. In support of this, the B- and C-class functions are remarkably conserved across angiosperms, and gymnosperm male and female cones also show $\mathrm{B}+\mathrm{C}$ and $\mathrm{C}$ gene expression, respectively (Sundström and Engström, 2002; Becker and Theissen, 2003; Zhang et al., 2004; Moyroud et al., 2017).

Therefore, the difference in gene expression between the perianth-less and bipartite perianth flower mainly resides in the peripheral expression domains of the $\mathrm{B}$ and $\mathrm{C}$ genes. This suggests that cadastral mechanisms that maintain (through repression or activation) $\mathrm{B}$ - and C-class gene expression to their dedicated area could have been key for perianth evolution. From reviewing the literature, it appears that several repressors of B- and C-class gene expression have been identified in extant species. Indeed, specifically repressing $\mathrm{B}$ genes from the first whorl and $\mathrm{C}$ genes from the first and second whorls is one possible way to generate a domain sufficient for sepal and petal

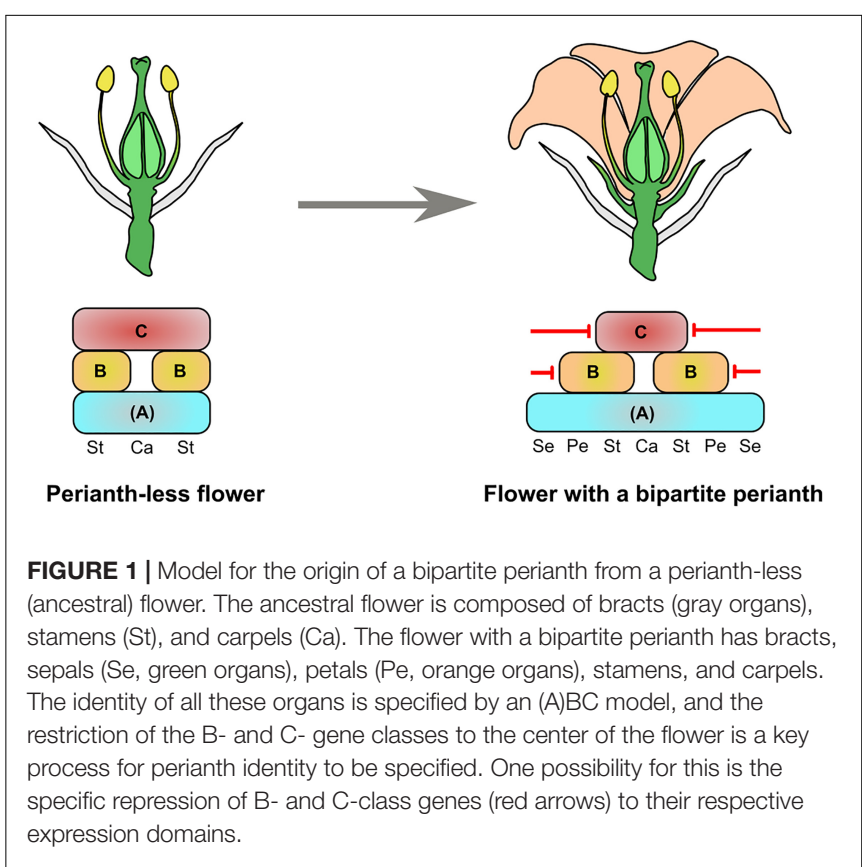


identity to be specified. In the following paragraphs we will review the repressors of $\mathrm{B}$ - and $\mathrm{C}$-class genes and examine how conserved their function is across angiosperms (Figure 2A). This review is mostly based on functional studies in the model species Arabidopsis thaliana (Arabidopsis), Petunia hybrida (Petunia), Oryza sativa (Rice), and Antirrhinum majus (Antirrhinum).

\section{REPRESSORS OF C-CLASS GENE EXPRESSION}

A-class genes from the classical ABC model were proposed, already from the beginning, to have a dual function in specifying organ identity in the first two whorls (sepals and petals, alone or in combination with B-genes), and repressing the $\mathrm{C}$ function from these same whorls (Coen and Meyerowitz, 1991). In Arabidopsis, APETALA1 $(A P 1)$ and AP2 are generally classified as A-class genes, although $A P 1$ was added only later to this class (Bowman et al., 1991; Coen and Meyerowitz, 1991; GustafsonBrown et al., 1994). Indeed, AP1 does repress C-class gene expression from young flowers, by forming complexes with the flower meristem identity regulators SHORT VEGETATIVE PHASE (SVP) or AGAMOUS-LIKE24 (AGL24) and the general floral repressors LEUNIG (LUG) and SEUSS (SEU) (Gregis et al., 2006, 2009; Sridhar et al., 2006). But examination of ap1 in combination with other mutations revealed that AP1 is not strictly necessary for petal and sepal identity, since these organs can develop in some ap1 mutant backgrounds (Yu et al., 2004; Causier et al., 2010). Moreover outside of Brassicaceae, AP1 orthologues are generally not needed for sepal and petal identity (Litt, 2007; Causier et al., 2010). For instance in Antirrhinum, mutant in the AP1 ortholog SQUAMOSA shows defects in floral meristem identity but not necessarily in perianth identity (Huijser et al., 1992). In contrast in Rice, mutations in the AP1/FRUITFUL (FUL) lineage members OsMADS14 and OsMADS15 results in the extension of C-class gene expression (and to a lesser extent, B-class gene expression) in the outer whorls of the flower, therefore leading to palea-tocarpel and lodicule-to-stamen homeotic conversions (Wu et al., 2017).

In Arabidopsis the other A-class gene AP2 represses AGAMOUS ( $A G$, the C-class gene) expression in whorls 1 and 2 , and the ap2 mutant shows the sepal-to-carpel and petal-tostamen homeotic conversions expected from an A-class mutant (Drews et al., 1991) (see Figure 2B for a simplified phylogeny of AP2-like genes). Both the AP2-type gene TARGET OF EAT 3 (TOE3) and the AP2-like gene AINTEGUMENTA (ANT) also repress $A G$ expression; however, homeotic changes in the corresponding mutants are very subtle, if any (Krizek et al., 2000; Jung et al., 2014). AP2 and TOE3 expression is regulated at the translational level by the microRNA miR172 (Chen, 2004; Wollmann et al., 2010). In Petunia, it was recently found that the euAP2 clade member BLIND ENHANCER (BEN), although not the ortholog of $A P 2$, also represses $C$-class gene expression from the first whorl (Morel et al., 2017); in maize mutations in the AP2-like genes $i d s 1$ and sid1 result in ectopic expression of the $A G$-like genes zag1 and $z m m 2$ in bracts that become carpelloid (Chuck et al., 2008); in other species antagonistic expression patterns suggest a similar repressive role of AP2-like genes on C-class gene expression (Yang et al., 2015). In contrast, the
A

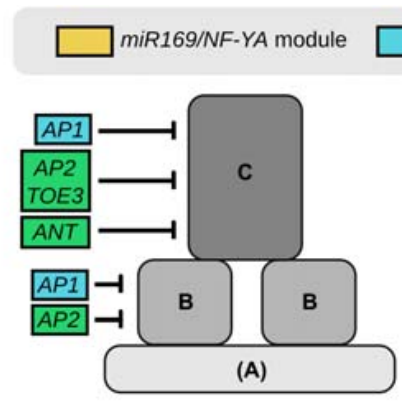

Arabidopsis thaliana

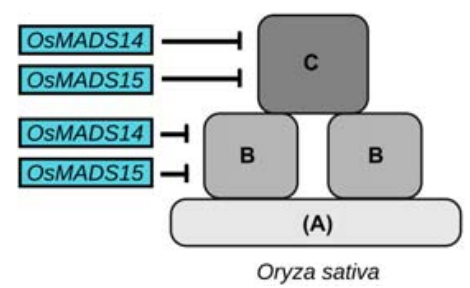

AP1/FUL-like genes $\square$ AP2-like genes
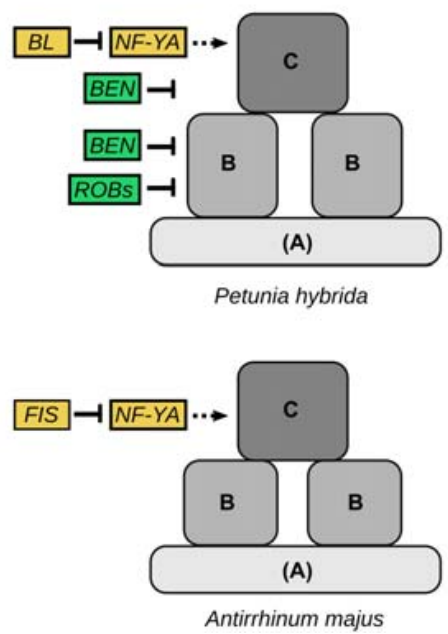

B

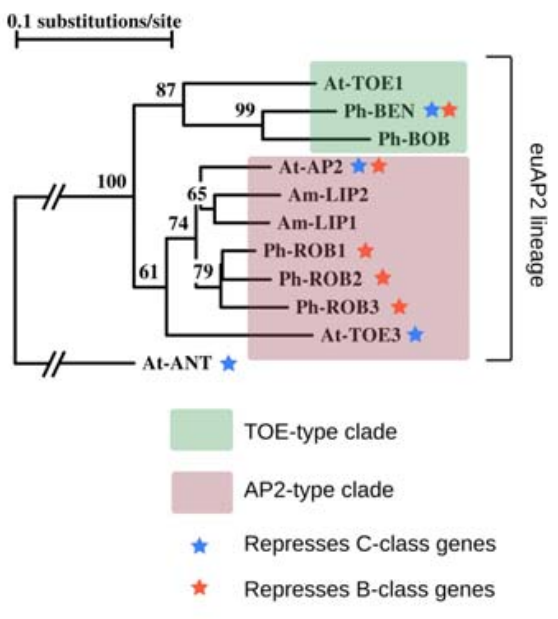

FIGURE 2 | (A) Summary of some of the regulators involved in B- and C-class gene repression in Arabidopsis, Petunia, Rice, and Antirrhinum. The color code indicates their membership to modules or gene families that were found to be recurrent between species. Dotted arrows for NF-YA indicate that their hypothetical role in C-gene activation has not been demonstrated so far. (B) Simplified phylogeny of AP2-like proteins, showing the euAP2 lineage composed of the TOE-type and AP2-type clades. Blue and orange stars indicate when the proteins were shown to repress C-class and B-class genes expression, respectively. Simplified from (Morel et al., 2017). At, Arabidopsis thaliana; Ph, Petunia hybrida; Am, Antirrhinum majus. 
Antirrhinum AP2 orthologs LIPLESS1 (LIP1) and LIP2, and the petunia AP2 orthologs REPRESSOR OF B-FUNCTION 1 (ROB1), $R O B 2$, and $R O B 3$ play a role in sepal and petal development but do not seem to antagonize C-class gene expression in the perianth (Keck et al., 2003; Morel et al., 2017). Overall, this shows that members of the euAP2 lineage are often involved in C-class gene repression in the outer whorls of the flower, but this role sometimes has been swapped between members of the lineage, switching between AP2-type and TOE-type clade members (Figure 2B). These two clades predate the monocoteudicot divergence (Kim et al., 2006), suggesting that the repression of $\mathrm{C}$-class genes by members of the euAP2 lineage might be relatively ancient.

In Arabidopsis, other C-class repressors have been identified: the SUPERMAN-like zinc finger protein RABBIT EARS (RBE) represses $A G$ in whorl 2 (Krizek et al., 2006), while the bZIP transcription factor PERIANTHIA (PAN), together with SEU, represses $A G$ in whorl 1 (Das et al., 2009; Wynn et al., 2014). However, mutations in these genes are not sufficient to cause homeotic changes in floral organs, showing that a certain threshold of $A G$ ectopic expression is needed for homeotic conversion. In contrast, completely different C-class repressor genes have been identified in Petunia and Antirrhinum. Indeed in both species a member of the miR169 family, BLIND (BL) in Petunia and FISTULATA (FIS) in Antirrhinum, represses $\mathrm{C}$-class gene expression in the outer whorls, possibly by targeting members of the NF-YA family for degradation (Cartolano et al., 2007). Members of the miR169/NF-YA module from various species have been involved in several developmental processes such as flowering time, root architecture, embryogenesis, general responses to stress or interaction with pathogens (Laloum et al., 2013; Zhao et al., 2016; Zanetti et al., 2017) but apart from Petunia and Antirrhinum, never in floral patterning. This specific function of miR169/NF-YA might thus have evolved only in the euasterids lineage, unless in rosids it is hidden by redundancy between the multiple copies of miR169 and NF-YA genes.

Other C-class repressors with a broader spatial action have been found, including BELLRINGER that represses $A G$ expression in the Arabidopsis stem, inflorescence meristem and young flower meristem (Bao et al., 2004); CURLY LEAF that represses $A G$ expression in all vegetative tissues of Arabidopsis and Brachypodium (Goodrich et al., 1997; Lomax et al., 2018); STERILE APETALA that represses $A G$ expression in the outer floral whorls and in the inflorescence meristem of Arabidopsis (Byzova et al., 1999); and FILAMENTOUS FLOWER that represses $A G$ expression in the outer floral whorls and in the peduncle of Arabidopsis (Chen et al., 1999). Mutations in each of these genes cause homeotic defects in Arabidopsis floral organs. The fact that these repressors are not spatially specific to the outer floral whorls does not exclude that they could have played a role in perianth evolution by being coopted for repression of $A G$ in whorls 1 and whorls 2, while they already repressed $A G$ expression from other tissues (True and Carroll, 2002). However, since their role has hardly been investigated in other species than Arabidopsis so far, we do not know how conserved these mechanisms are and if they could have been involved in perianth evolution.

\section{REPRESSORS OF B-CLASS GENE EXPRESSION}

In contrast to the many $\mathrm{C}$-class genes repressor identified, fewer genes have been shown to repress B-class gene expression from the first whorl of the flower (Figure 2). In Arabidopsis, AP2 represses the B-class genes APETALA3 (AP3) and PISTILLATA $(P I)$ expression in whorl 1. While this is not evident from the phenotype of single ap2 mutants, this becomes visible when an ap2 mutant allele is present in an heterozygous state in the topless ( $t p l)$ mutant background, resulting in a partial sepal-topetal conversion due to ectopic PI and AP3 expression in whorl 1 (Krogan et al., 2012). But by far, the clearest evidence of B-class gene derepression in whorl 1 is found in Petunia in the quadruple ben rob1 rob2 rob3 mutant, that shows an almost perfect homeotic conversion of sepals into petals (Morel et al., 2017). As such this flower is reminiscent of the undifferentiated perianth found in many angiosperm species, such as tulip or magnolia, and likely a characteristic trait of the ancestral flower (Sauquet et al., 2017). As previously mentioned, BEN and ROBs are all members of the euAP2 lineage (Figure 2B). The single ben mutant also shows some petaloid sectors in sepals, indicating that BEN and ROBs partially redundantly repress B-genes expression in whorl 1 (Morel et al., 2017). Therefore, repression of B-genes expression by euAP2 genes appears conserved between Arabidopsis and Petunia, suggesting that this regulation might have originated prior to the rosids-asterids divergence.

APETALA1 has also been proposed to repress PI and AP3 expression in Arabidopsis, when part of the repressive complex with AGL24, SVP, LUG, and SEU (Gregis et al., 2006, 2009), but whether AP1 is directly involved in this regulation is unclear. In Rice the osmads14 osmads15 double mutant shows some derepression of B-class gene expression in whorl 1 but this ectopic expression does not seem strong enough to alter organ identity (Wu et al., 2017). Altogether, this suggests a somehow conserved role of $A P 1 / F U L$ genes in repressing $\mathrm{B}$-class gene expression but the evidence is scarcer than for AP2 genes.

\section{CONSERVED AND UNIQUE REPRESSORS OF B- AND C-CLASS GENES}

Our review highlights that members of the large AP2 family, and in particular the euAP2 lineage, might have a conserved function in repressing both $\mathrm{B}$ - and $\mathrm{C}$-class gene expression from the outer whorls of the flower, predating the rosids-asterids divergence. Hence members from this family are possible candidates to have played a role in perianth evolution. However, if euAP2 genes were involved in both sepal and petal evolution, it would require uncoupling of their repressive action on B- and C-class genes, since B-class genes should be repressed in the first whorl only while C-class genes should be repressed in the first two whorls. In Arabidopsis, it is unknown how AP2 can have whorl-specific repressive action on $\mathrm{B}$ - and $\mathrm{C}$-class genes, but it possibly resides in the interaction with different protein partners between whorls. 
In Petunia, euAP2 proteins repress $\mathrm{B}$ - and C-gene expression in the first whorl only, while repression of $\mathrm{C}$-class genes in the second whorl is completed by $B L$, showing how the dual repressive function has been distributed between two sets of genes in this species. More functional studies in angiosperms, and particularly in early diverging taxa, are now needed to evaluate the possibility that euAP2 genes were involved in perianth evolution.

Our review also shows that a large variety of repressors of C- (and to a more minor extent, B-) class genes exist in extant species. One might wonder in particular why so many $\mathrm{C}$-genes repressors are found. None of the identified repressors are redundant with each other since single mutants in question all show ectopic $\mathrm{C}$ expression. Hence instead of conferring robust repression of $\mathrm{C}$-class genes expression, these numerous repressors might actually provide a multiplicity of ways for evolution to relieve C-expression in the perianth. Since the perianth is a highly evolvable structure, i.e., a flexible trait that evolved multiple times during angiosperm evolution (Baum and Whitlock, 1999; Kramer and Irish, 2000; Hileman and Irish, 2009; Geuten et al., 2011), an hypothesis is that evolution could have tinkered with these various repressors for the perianth to appear or disappear in different taxa.

Petaloid features are not exclusively found on second whorl petals but often have been transferred to sepals, bracts or even stamens. Flower morphology is remarkably flexible and while true petals may have been lost, petaloidy shifted to analogous organs that acquired the petal traits needed for recognition by pollinators. These petaloid features are sometimes correlated with ectopic B-gene expression, like in many non-grass monocots for instance (Kanno et al., 2007), but there are also many cases of petaloid structures that have little or no B-genes expression, as well as non-petaloid structures that do express B-class genes, as reviewed in (Ronse De Craene and Brockington, 2013). We can argue that not all B-class genes might have been identified in species without a sequenced genome. Still, the evolution of

\section{REFERENCES}

Bao, X., Franks, R. G., Levin, J. Z., and Liu, Z. (2004). Repression of AGAMOUS by BELLRINGER in floral and inflorescence meristems. Plant Cell 16, 1478-1489. doi: 10.1105/tpc.021147

Baum, D. A., and Hileman, L. C. (2007). "A developmental genetic model for the origin of the flower," in Annual Plant Reviews: Flowering and its Manipulation, Vol. 20, ed. C. Ainsworth (Chichester: Blackwell Publishing Ltd), 1-27. doi: 10.1002/9780470988602.ch1

Baum, D. A., and Whitlock, B. A. (1999). Plant development: genetic clues to petal evolution. Curr. Biol. 9, R525-R527. doi: 10.1016/S0960-9822(99)80327-3

Becker, A., and Theissen, G. (2003). The major clades of MADS-box genes and their role in the development and evolution of flowering plants. Mol. Phylogenet. Evol. 29, 464-489. doi: 10.1016/S1055-7903(03)00207-0

Bowman, J. L., Smyth, D. R., and Meyerowitz, E. M. (1991). Genetic interactions among floral homeotic genes of Arabidopsis. Development $112,1-20$.

Brockington, S. F., Rudall, P. J., Frohlich, M. W., Oppenheimer, D. G., Soltis, P. S., and Soltis, D. E. (2012). 'Living stones' reveal alternative petal identity programs within the core eudicots. Plant J. 69, 193-203. doi: 10.1111/j.1365-313X.2011. 04797.x petaloidy appears to be more complex than mere shifts in B-class gene expression, and the genes underlying these transfers of function from one organ to another might still remain to be identified.

\section{CONCLUSION}

In this review we proposed that repressing reproductive organ identity to the center of the flower is a possible way for perianth identity to have emerged in the periphery of the flower, and we reviewed the $\mathrm{B}$ - and $\mathrm{C}$-class genes repressors that have been identified in model species. Whether these repressors were actually evolved in perianth evolution some 150 million years ago remains of course hypothetical, and functional experiments in early-diverging gymnosperms and angiosperms are needed to evaluate such hypotheses. By far the largest source of variation in perianth morphology in angiosperms does not lie in flower patterning, but in changes in shape, color, scent or size of the petals, as beautifully illustrated in (Byng et al., 2018). The genetic basis for these variations, some of quantitative nature like spur length in Aquilegia (Yant et al., 2015), others of qualitative nature like presence or absence of pigmentation in Petunia (Hoballah et al., 2007), has only been identified on few occasions (Moyroud and Glover, 2017). These genes are likely downstream targets of B-class regulators, but how these master developmental genes direct the establishment of all petaloid features in a simultaneous manner, and which parts of this large network have been modified during evolution to generate morphological diversity, remains a mystery as big as perianth evolution itself.

\section{AUTHOR CONTRIBUTIONS}

All authors listed have made a substantial, direct and intellectual contribution to the work, and approved it for publication.

Byng, J. W., Smets, E. F., van Vugt, R., Bidault, E., Davidson, C., Kenicer, G., et al. (2018). Angiosperm Poster. Plant Gateway. Available at: http://www.plantgateway.com/poster/ [accessed April $25,2018]$.

Byzova, M. V., Franken, J., Aarts, M. G., de Almeida-Engler, J., Engler, G., Mariani, C., et al. (1999). Arabidopsis STERILE APETALA, a multifunctional gene regulating inflorescence, flower, and ovule development. Genes Dev. 13, 1002-1014. doi: 10.1101/gad.13.8.1002

Cartolano, M., Castillo, R., Efremova, N., Kuckenberg, M., Zethof, J., Gerats, T., et al. (2007). A conserved microRNA module exerts homeotic control over Petunia hybrida and Antirrhinum majus floral organ identity. Nat. Genet. 39, 901-905. doi: 10.1038/ng2056

Causier, B., Schwarz-Sommer, Z., and Davies, B. (2010). Floral organ identity: 20 years of ABCs. Semin. Cell Dev. Biol. 21, 73-79. doi: 10.1016/j.semcdb.2009. 10.005

Chen, Q., Atkinson, A., Otsuga, D., Christensen, T., Reynolds, L., and Drews, G. N. (1999). The Arabidopsis FILAMENTOUS FLOWER gene is required for flower formation. Development 126, 2715-2726.

Chen, X. (2004). A MicroRNA as a translational repressor of APETALA2 in Arabidopsis flower development. Science 303, 2022-2025. doi: 10.1126/science. 1088060 
Chuck, G., Meeley, R., and Hake, S. (2008). Floral meristem initiation and meristem cell fate are regulated by the maize AP2 genes ids1 and sid1. Development 135, 3013-3019. doi: 10.1242/dev.024273

Coen, E. S., and Meyerowitz, E. M. (1991). The war of the whorls: genetic interactions controlling flower development. Nature 353, 31-37. doi: 10.1038/ $353031 \mathrm{a} 0$

Das, P., Ito, T., Wellmer, F., Vernoux, T., Dedieu, A., Traas, J., et al. (2009). Floral stem cell termination involves the direct regulation of AGAMOUS by PERIANTHIA. Development 136, 1605-1611. doi: 10.1242/dev.035436

Drews, G. N., Bowman, J. L., and Meyerowitz, E. M. (1991). Negative regulation of the Arabidopsis homeotic gene AGAMOUS by the APETALA2 product. Cell 65, 991-1002. doi: 10.1016/0092-8674(91)90551-9

Fenster, C. B., Armbruster, W. S., Wilson, P., Dudash, M. R., and Thomson, J. D. (2004). Pollination syndromes and floral specialization. Annu. Rev. Ecol. Evol. Syst. 35, 375-403. doi: 10.1146/annurev.ecolsys.34.011802.132347

Frohlich, M. W., and Chase, M. W. (2007). After a dozen years of progress the origin of angiosperms is still a great mystery. Nature 450, 1184-1189. doi: 10.1038 /nature06393

Geuten, K., Viaene, T., and Irish, V. F. (2011). Robustness and evolvability in the B-system of flower development. Ann. Bot. 107, 1545-1556. doi: 10.1093/aob/ mcr061

Glover, B. (2014). Understanding Flowers and Flowering, 2nd Edn. Oxford: Oxford University Press. doi: 10.1093/acprof:oso/9780199661596.001. 0001

Goodrich, J., Puangsomlee, P., Martin, M., Long, D., Meyerowitz, E. M., and Coupland, G. (1997). A Polycomb-group gene regulates homeotic gene expression in Arabidopsis. Nature 386, 44-51. doi: 10.1038/3860 $44 \mathrm{a} 0$

Gregis, V., Sessa, A., Colombo, L., and Kater, M. M. (2006). AGL24, SHORT VEGETATIVE PHASE, and APETALA1 redundantly control AGAMOUS during early stages of flower development in Arabidopsis. Plant Cell 18, 1373-1382. doi: 10.1105/tpc.106.041798

Gregis, V., Sessa, A., Dorca-Fornell, C., and Kater, M. M. (2009). The Arabidopsis floral meristem identity genes AP1, AGL24 and SVP directly repress class B and C floral homeotic genes. Plant J. 60, 626-637. doi: 10.1111/j.1365-313X.2009. 03985.x

Gustafson-Brown, C., Savidge, B., and Yanofsky, M. F. (1994). Regulation of the Arabidopsis floral homeotic gene APETALA1. Cell 76, 131-143. doi: 10.1016/ 0092-8674(94)90178-3

Heijmans, K., Morel, P., and Vandenbussche, M. (2012). MADS-box genes and floral development: the dark side. J. Exp. Bot. 63, 5397-5404. doi: 10.1093/jxb/ ers 233

Hileman, L. C., and Irish, V. F. (2009). More is better: the uses of developmental genetic data to reconstruct perianth evolution. Am. J. Bot. 96, 83-95. doi: 10.3732/ajb.0800066

Hoballah, M. E., Gubitz, T., Stuurman, J., Broger, L., Barone, M., Mandel, T., et al. (2007). Single gene-mediated shift in pollinator attraction in Petunia. Plant Cell 19, 779-790. doi: 10.1105/tpc.106.048694

Huijser, P., Klein, J., Lonnig, W. E., Meijer, H., Saedler, H., and Sommer, H. (1992). Bracteomania, an inflorescence anomaly, is caused by the loss of function of the MADS-box gene squamosa in Antirrhinum majus. EMBO J. 11, 1239-1249. doi: 10.1002/j.1460-2075.1992.tb05168.x

Jung, J.-H., Lee, S., Yun, J., Lee, M., and Park, C.-M. (2014). The miR172 target TOE3 represses AGAMOUS expression during Arabidopsis floral patterning. Plant Sci. 21, 29-38. doi: 10.1016/j.plantsci.2013.10.010

Kanno, A., Nakada, M., Akita, Y., and Hirai, M. (2007). Class B gene expression and the modified ABC model in nongrass monocots. Sci. World J. 7, 268-279. doi: 10.1100/tsw.2007.86

Keck, E., McSteen, P., Carpenter, R., and Coen, E. (2003). Separation of genetic functions controlling organ identity in flowers. EMBO J. 22, 1058-1066. doi: 10.1093/emboj/cdg097

Kim, S., Soltis, P. S., Wall, K., and Soltis, D. E. (2006). Phylogeny and domain evolution in the APETALA2-like gene family. Mol. Biol. Evol. 23, 107-120. doi: $10.1093 / \mathrm{molbev} / \mathrm{msj} 014$

Kramer, E. M., and Irish, V. F. (2000). Evolution of the petal and stamen developmental programs: evidence from comparative studies of the lower eudicots and basal angiosperms. Int. J. Plant Sci. 161, S29-S40. doi: 10.1086/ 317576
Krizek, B. A., Lewis, M. W., and Fletcher, J. C. (2006). RABBIT EARS is a secondwhorl repressor of AGAMOUS that maintains spatial boundaries in Arabidopsis flowers. Plant J. 45, 369-383. doi: 10.1111/j.1365-313X.2005.02633.x

Krizek, B. A., Prost, V., and Macias, A. (2000). AINTEGUMENTA promotes petal identity and acts as a negative regulator of AGAMOUS. Plant Cell 12, 1357-1366. doi: 10.1105/tpc.12.8.1357

Krogan, N. T., Hogan, K., and Long, J. A. (2012). APETALA2 negatively regulates multiple floral organ identity genes in Arabidopsis by recruiting the co-repressor TOPLESS and the histone deacetylase HDA19. Development 139, 4180-4190. doi: 10.1242/dev.085407

Laloum, T., De Mita, S., Gamas, P., Baudin, M., and Niebel, A. (2013). CCAATbox binding transcription factors in plants: Y so many? Trends Plant Sci. 18, 157-166. doi: 10.1016/j.tplants.2012.07.004

Litt, A. (2007). An evaluation of A-function: evidence from the APETALA1 and APETALA2 gene lineages. Int. J. Plant Sci. 168, 73-91. doi: 10.1086/509662

Lomax, A., Woods, D. P., Dong, Y., Bouché, F., Rong, Y., Mayer, K. S., et al. (2018). An ortholog of CURLY LEAF/ENHANCER OF ZESTE like-1 is required for proper flowering in Brachypodium distachyon. Plant J. 93, 871-882. doi: $10.1111 /$ tpj.13815

Morel, P., Heijmans, K., Rozier, F., Zethof, J., Chamot, S., Bento, S. R., et al. (2017). Divergence of the floral A-function between an asterid and a Rosid Species. Plant Cell 29, 1605-1621. doi: 10.1105/tpc.17.00098

Moyroud, E., and Glover, B. J. (2017). The evolution of diverse floral morphologies. Curr. Biol. 27, R941-R951. doi: 10.1016/j.cub.2017.06.053

Moyroud, E., Monniaux, M., Thévenon, E., Dumas, R., Scutt, C. P., Frohlich, M. W., et al. (2017). A link between LEAFY and B-gene homologues in Welwitschia mirabilis sheds light on ancestral mechanisms prefiguring floral development. New Phytol. 216, 469-481. doi: 10.1111/nph.14483

Regal, P. J. (1977). Ecology and evolution of flowering plant dominance. Science 196, 622-629. doi: 10.1126/science.196.4290.622

Ronse De Craene, L. P., and Brockington, S. F. (2013). Origin and evolution of petals in angiosperms. Plant Ecol. Evol. 146, 5-25. doi: 10.5091/plecevo.20 13.738

Ronse De Craene, R. D. (2007). Are petals sterile stamens or bracts? The origin and evolution of petals in the core eudicots. Ann. Bot. 100, 621-630. doi: $10.1093 / \mathrm{aob} / \mathrm{mcm} 076$

Sauquet, H., and Magallón, S. (2018). Key questions and challenges in angiosperm macroevolution. New Phytol. 219, 1170-1187. doi: 10.1111/nph.15104

Sauquet, H., von Balthazar, M., Magallón, S., Doyle, J. A., Endress, P. K., Bailes, E. J., et al. (2017). The ancestral flower of angiosperms and its early diversification. Nat. Commun. 8:16047. doi: 10.1038/ncomms16047

Schwarz-Sommer, Z., Huijser, P., Nacken, W., Saedler, H., and Sommer, H. (1990). Genetic control of flower development by homeotic genes in Antirrhinum majus. Science 250, 931-936. doi: 10.1126/science.250.4983.931

Scutt, C. P. (2018). “The origin of angiosperms," in Evolutionary Developmental Biology, eds L. Nuno de la Rosa and G. Müller (Cham: Springer International Publishing), 1-20. doi: 10.1007/978-3-319-33038-9_60-1

Specht, C. D., and Bartlett, M. E. (2009). Flower evolution: the origin and subsequent diversification of the angiosperm flower. Annu. Rev. Ecol. Evol. Syst. 40, 217-243. doi: 10.1146/annurev.ecolsys.110308.120203

Sridhar, V. V., Surendrarao, A., and Liu, Z. (2006). APETALA1 and SEPALLATA3 interact with SEUSS to mediate transcription repression during flower development. Development 133, 3159-3166. doi: 10.1242/dev.02498

Sundström, J., and Engström, P. (2002). Conifer reproductive development involves B-type MADS-box genes with distinct and different activities in male organ primordia. Plant J. 31, 161-169. doi: 10.1046/j.1365-313X.2002.01343.x

The Plant List (2013). Available at: http://www.theplantlist.org/

True, J. R., and Carroll, S. B. (2002). Gene co-option in physiological and morphological evolution. Annu. Rev. Cell Dev. Biol. 18, 53-80. doi: 10.1146/ annurev.cellbio.18.020402.140619

van Doorn, W. G., and Van Meeteren, U. (2003). Flower opening and closure: a review. J. Exp. Bot. 54, 1801-1812. doi: 10.1093/jxb/erg213

Wollmann, H., Mica, E., Todesco, M., Long, J. A., and Weigel, D. (2010). On reconciling the interactions between APETALA2, miR172 and AGAMOUS with the ABC model of flower development. Development 137, 3633-3642. doi: 10.1242/dev.036673

Wu, F., Shi, X., Lin, X., Liu, Y., Chong, K., Theißen, G., et al. (2017). The ABCs of flower development: mutational analysis of AP1/FUL-like genes in rice 
provides evidence for a homeotic (A)-function in grasses. Plant J. 89, 310-324. doi: 10.1111/tpj.13386

Wynn, A. N., Seaman, A. A., Jones, A. L., and Franks, R. G. (2014). Novel functional roles for PERIANTHIA and SEUSS during floral organ identity specification, floral meristem termination, and gynoecial development. Front. Plant Sci. 5:130. doi: $10.3389 /$ fpls.2014.00130

Yang, F. X., Zhu, G. F., Wang, Z., Liu, H. L., and Huang, D. (2015). A putative miR172-targeted CeAPETALA2-like gene is involved in floral patterning regulation of the orchid Cymbidium ensifolium. Genet. Mol. Res. 14, 12049-12061. doi: 10.4238/2015.October.5.18

Yant, L., Collani, S., Puzey, J., Levy, C., and Kramer, E. M. (2015). Molecular basis for three-dimensional elaboration of the Aquilegia petal spur. Proc. Biol. Sci. 282:20142778. doi: 10.1098/rspb.2014.2778

Yu, H., Ito, T., Wellmer, F., and Meyerowitz, E. M. (2004). Repression of AGAMOUS-LIKE 24 is a crucial step in promoting flower development. Nat. Genet. 36, 157-161. doi: 10.1038/ng1286

Zanetti, M. E., Rípodas, C., and Niebel, A. (2017). Plant NF-Y transcription factors: key players in plant-microbe interactions, root development and adaptation to stress. Biochim. Biophys. Acta 1860, 645-654. doi: 10.1016/j.bbagrm.2016.11.007
Zhang, P., Tan, H. T. W., Pwee, K.-H., and Kumar, P. P. (2004). Conservation of class C function of floral organ development during 300 million years of evolution from gymnosperms to angiosperms. Plant J. 37, 566-577. doi: 10.1046/j.1365-313X.2003.01983.x

Zhao, H., Wu, D., Kong, F., Lin, K., Zhang, H., and Li, G. (2016). The Arabidopsis thaliana nuclear factor Y transcription factors. Front. Plant Sci. 7:2045. doi: $10.3389 /$ fpls.2016.02045

Conflict of Interest Statement: The authors declare that the research was conducted in the absence of any commercial or financial relationships that could be construed as a potential conflict of interest.

Copyright (c) 2018 Monniaux and Vandenbussche. This is an open-access article distributed under the terms of the Creative Commons Attribution License (CC BY). The use, distribution or reproduction in other forums is permitted, provided the original author(s) and the copyright owner(s) are credited and that the original publication in this journal is cited, in accordance with accepted academic practice. No use, distribution or reproduction is permitted which does not comply with these terms. 